\title{
Como um vento lá fora que dizia...
}

\author{
Nuno Pino Custódio
}

Teve a duração de vinte minutos o primeiro espectáculo da Estação Teatral. Soava a todos um tempo tão curto quanto curta era na verdade a existência da companhia ainda em finais de 2004. Sem dinheiro que não fosse 0 (pouco) dos bolsos de cada um, sem equipamento, ferramentas ou espaço próprio, parecia também curto 0 futuro. Percebia-se no ar aquela espécie de precariedade que nasce da liberdade, do impulso de romper com a realidade e procurar no incerto, no desconhecido, fosse onde fosse, a oportunidade de se criar um projecto de raiz.

Mas aqueles vinte minutos também faziam vislumbrar um nascimento. É que a companhia tinha as pessoas, 0 que significava, neste caso particular, autonomia no respeitante à criação dramatúrgica, à encenação e à formação de actores. A Estação Teatral podia fazer o espectáculo que quisesse, como quisesse, dentro do luxo e da sumptuosidade que era a sua pobreza. Havia um espaço vazio com uma cortina suja ao fundo. Havia uma actriz com uma máscara. Havia, então, um conector directo entre os que mostravam e os que viam, olhos nos olhos; e aqueles vinte minutos também faziam acreditar outros tantos.

Neste intervalo em que se contava uma história e se evocavam vinte minutos - de um outro tempo presente - sobrepostos aos do quotidiano de referência de cada um, encontravam-se, em potência, todas as linhas programáticas de um projecto cuja dimensão local e universal mais não era do que a união de tranças que fariam uma mesma corda. Os actores viam os espectadores e eram espectadores dos espectadores, numa constante adaptação; as palavras não seriam mais importantes do que as posturas, os movimentos, os gestos ou as acções e ... vice-versa; os encontros estabeleciam-se pela simples mudança de um "com os espectadores", ao invés daquele (tantas vezes subconsciente) "para os espectadores"; as criações, em plena temporada, "com os espectadores", evoluiam, assim, como se fossem peças inacabadas - e algo puramente do teatro brotava ali, jamais previsto numa folha branca, num écran vazio ou diante de cadeiras sem pessoas. As cenas, as acções, as falas reescreviamse, viravam-se do avesso, ramificavam-se, deixavam-se crescer, podavam-se, sintetizavam-se radicalmente, expandiam-se, aceleravam-se, sofriam implantações, desfocavam-se, degeneravam noutras, deixavam-se aqui e ali somente esboçadas para se perceber, primeiro, o que se não queria, porque haveria sempre de existir um tempo, uma imensa inquietação que não estava perdida no mundo, um compasso que seguia de mão dada com a aceitação serena de que a vida é movimento, de que o pó aparecerá, os pneus gastar-se-ão, os cabelos ficarão grisalhos, as folhas irão cair, as nuvens passarão e nada mais voltará a ser como dantes, nem sequer a forma de ver as coisas que se julgam ser as mesmas.

Contemporânea ao espaço do ensaio e da representação, a dramaturgia construía-se no próprio acto de ver (num ver bem mais amplo que o sentido da visão) e dizia-se já por ali, tal como o poeta, que "ver é sentir". Os objectos não se registavam senão nos corpos. Estavam vivos, os objectos e os corpos, e havia uma escrita que era a do espaço; melhor, a do movimento e do espaço; melhor, a da plasticidade dos corpos em acção no espaço. E seria deste, sempre, que tudo deveria partir.

Daquele espaço nu com uma cortina suja ao fundo e uma actriz à frente com uma máscara. Daqueles vinte minutos que agora, depois de tantos cortes e modificações, já eram trinta e dois... Estava tudo lá, em finais de 2004, na bela vila serrana de Alpedrinha, que no seu Teatro Clube acolheu, como se the pertencesse, uma nova companhia.

Quando Mãe preta, a primeira de todas as criações, chegou à cidade do Mindelo, Ilha de São Vicente, Cabo Verde, como que devolvida ao seu chão, durava já um pouco mais. Tinham passado dois anos. Cerca de seis dezenas de espectáculos em contextos tão díspares quanto antagónicos já faziam aceitar uma folha de papel. Eram três da manhã no terraço da residencial Sôdade quando, com a baía do Porto Grande pela frente e o Monte Cara adormecido, respirando lentamente aquele ar húmido e perfumado que inebria qualquer viajante acabado de aterrar, se escreveram os últimos sopros de uma personagem para a representação dias depois:

[...] houve uma vez um vento, um vento lá fora que dizia: esta ilha é como o chão liso para que possas ver ao longe o monte onde hásde semear...

E assim se fixaram os últimos três minutos que perfariam cinquenta e cinco. Mãe preta chegaria ao fim pouco depois. Nascia a Estação Teatral.

A Beira Interior, costuma dizer-se, é uma ilha. Uma ilha sem mar. Seria ali - e dali para tantas e tantas cidades portuguesas, também para Salamanca, Berlim ou Rio de
Nuno Pino Custódio é encenador e professor de teatro e desenvolve uma metodologia de trabalho com máscara desde $o$ início dos anos noventa. Investiga essencialmente 0 trabalho com máscara neutra e a commedia dell'arte, na perspectiva da formação do actor. É construtor de máscaras, autor de textos para teatro $O$ relato de Alabad, Mãe preta, $A$ verdadeira história da tomada do Carvalhal, entre outros - e dirige, desde 2004 a estrutura que fundou com colegas da região: ESTE - Estação Teatral da Beira Interior. Já encenou na Companhia do Chapitô, no Teatro Meridional, no Teatro da Serra de Montemuro ou n'O Bando, num total de cerca de quatro dezenas de trabalhos, quase todos originais ou em regime de cocriação. 
Janeiro - que se faria o chão liso desta pequena unidade, a distância onde, de um ponto a outro, se percebesse e se sentisse a sua criação.

Fazer um projecto artístico, com uma linguagem própria, num contexto tão específico como o da cidade do Fundão, com os seus oito mil habitantes e um concelho pululado de vilas e aldeias tão dispersas e tão pequenas, impunha à partida a projecção do teatro como real necessidade. Ou estaria votado a um punhado de dias com as cadeiras vazias até que definhasse. Real necessidade, aqui, só pode ter a pretensão de uma empresa que busca deveras a interdependência com a sua comunidade. Desde logo, havia que aspirar a um teatro popular, sem receio algum nem da palavra nem do imenso preconceito que esta gera em Portugal. Não significa pobre, fácil, ligeiro, imperfeito, superficial, desengajado, entretido, morto, moribundo, vulgar. Mas democratizável, na acepção brechtiana, "facilmente entendivel por todos".

E aqui caberia agora toda uma metodologia que, desde o início da minha actividade, no começo dos anos noventa, desenvolvia e explorava a máscara enquanto instrumento estruturante na formação do actor, um perfeito sistema - e como são raros no Ocidente os sistemas de interpretação, se não levarmos em conta variantes e escolas! Utensilio do passado, do antigo, ferramenta incontornável em períodos-charneira da história do teatro, a máscara sempre me proporcionou a criação de movimentos para o centro, no sentido de uma essência, de uma estrutura imutável, intemporal, de uma verdade (na acepção filosófica do termo) que me faz pensar, com enorme clareza, uma necessidade para o teatro, hoje. Entenda-se, uma actividade onde se resolva a falta de concomitância que está aí tão vigente entre 0 acto de fazer e o acto de ver, onde a não-verbalidade e a verbalidade finalmente dialoguem (ao invés de se subordinarem) e onde a dramaturgia e a encenação estabeleçam um enclave, uma zona onde, na transmissão de uma para a outra, exista apenas e só... teatro. A máscara não é um fim, mas um conector directo entre os que fazem e os que vêem. Pode ser retirada enquanto objecto que oculta total ou parcialmente um rosto mantendo-se intacto um comportamento que promove o desdobramento, a concentração, o encontro, a verosimilhança, o amor, o jogo, a presença.
A Estação Teatral é, assim, um projecto cujo contexto está dependente de uma metodologia e é também uma metodologia que se alimenta de um contexto e que só pode ser expressada por um colectivo. Findos praticamente oito anos de actividade, não existe na companhia menos do que uma relação de cumplicidade e parceria com a sua comunidade, e uma corrente de público deveras assinalável. Falo, portanto, de um projecto que, se desaparecesse agora, deprimiria de forma evidente toda uma cidade, muito possivelmente a sua região. Mais do que nunca, o teatro é hoje uma máquina que só funciona se humanizar. E tal significa, no seu contexto especifico, transmutar um "eu" num "outro", deixando esta extraordinária afirmação: "eu não sou eu". Portanto, "eu somos nós".

A sua actividade é, assim, um trabalho de continuidade(s). Há, desde a sua origem, um projecto pedagógico, intitulado "Uma história para continuar...", que envolve a comunidade escolar do concelho e a implica com o processo final, a criação. Há as Classes, onde as ferramentas, as metodologias, os princípios estruturantes da companhia se transmitem a crianças e adolescentes e daqui já se fazem novos espectadores ou até, profissionalmente falando, colaboradores. Há um festival que já vai na sua oitava edição, o TeatroAgosto, hoje denominado "festival internacional de teatro ao ar livre". Há a criação, a programação, um ciclo de dramaturgias, o Ciclo Invasões, onde se perscruta a identidade de uma região e se percebe a sua dimensão universal. Há a pesquisa a partir de obras clássicas, onde se desenvolve, finalmente, uma "ideia de teatro" que norteia o percurso da companhia. Há a perspectiva de uma escola, onde as formações de Verão já envolvem actores profissionais e alunos oriundos das mais diversas escolas do pais. E há, finalmente, a enorme vertente de itinerância como perspectiva de aprendizagem na adaptação e flexibilização a realidades distintas. Fizeram-se até hoje vinte criações, todas com dramaturgia original, na perspectiva de firmar uma necessidade real para um público de hoje, sendo já três as peças publicadas.

E há ainda o vento, o vento lá fora que nos diz:

[...] esta ilha é como o chão liso para que possamos ver ao longe o monte onde havemos de semear.. 


\section{Legendas}

\section{Mãe preta,}

texto e encenação de Nuno Pino Custódio,

Estação Teatral, 2004

(Sandra Horta),

fot. António Supico.

\section{$2|3| 4|5| 6|7| 8 \mid 9$}

Pax Romana,

de Nuno Pino Custódio/Estação Teatral,

enc. Nuno Pino Custódio, Estação Teatral, 2006

(2 > Pedro Diogo, Sérgio Fernandes e Alexandre Barata;

$3 \mid 6>$ Pedro Diogo;

$4 \mid 5$ > Pedro Diogo e Sérgio Fernandes;

$7>$ Alexandre Barata;

$8 \mid 9>$ Pedro Diogo, Sérgio Fernandes e Alexandre Barata) fot. Ricardo Brito.

$10|11| 12|13| 14|15| 16$

A verdadeira história da tomada do Carvalhal,

texto e enc. Nuno Pino Custódio,

Estação Teatral, 2007

(10 > António Supico, José Emilio Martins, Leonor Cabral e Rui M. Silva;

11 > José Emilio Martins, Leonor Cabral, Rui M. Silva,

Carlos Pereira e Ricardo Brito;

12 > Carlos Pereira e Leonor Cabral;

13x > Carlos Perira, Leonor Cabral e Rui M. Silva;

14 > António Supico, Carlos Pereira, Rui M. Silva,

Ricardo Brito e Leonor Cabral;

15 > António Supico, Rui M. Silva, José Emilio Martins,

Leonor Cabral, Alexandre Barata, Carlos Pereira

e Ricardo Brito:

$16>$ Carlos Pereira e Leonor Cabral),

fot. Gustavo Medeiros.
$17|18| 19|20| 21|22| 23$

Cozinheiros,

a partir de A cozinha (1957), de Arnold Wesker,

enc. Nuno Pino Custódio,

Estação Teatral, 2009, des. Marta Carreiras.

(17 > Carlos Pereira, Alexandre Barata, Pedro Diogo

e Ricardo Brito;

18 | 19 > Carlos Pereira, Pedro Diogo, Alexandre Barata e Ricardo Brito;

20 | 23 > Pedro Diogo e Alexandre Barata;

$21>$ Carlos Pereira;

$22>$ Pedro Diogo),

fot. António Supico.

24 | 25 | 26 | 27

As cebolas de Napoleão,

de Nuno Pino Custódio/Estação Teatral,

enc. Nuno Pino Custódio, Estação Teatral, 2010

(24> Ricardo Brito, Patrick Murys e Tiago Poiares;

25> Tiago Poiares e Patrick Murys:

26> Ricardo Brito;

27> Patrick Murys),

fot. António Supico.
$28|29| 30|31| 32|33| 34|35| 36$

Volfrâmio,

de Nuno Pino Custódio/Estação Teatral,

enc. Nuno Pino Custódio, Estação Teatral, 2011

(28 > Ricardo Brito, Fabiola Lebre e Yolanda Santos;

29 > Fabiola Lebre e Tiago Poiares:

30 > Tiago Poiares, Ricardo Brito, Fabiola Lebre

e Yolanda Santos;

31 > Yolanda Santos, Ricardo Brito, Fabiola Lebre

e Tiago Poiares;

$32>$ Yolanda Santos:

33 > Tiago Poiares;

34> Fabiola Lebre, Ricardo Brito, Yolanda Santos

e Tiago Poiares;

35> Tiago Poiares e Fabiola Lebre;

$36>$ Yolanda Santos e Ricardo Brito)

fot. António Supico.

37 | 38 | 39 | 40

$1>$ Cozinheiros versão Commedia dell'Arte

De Nuno Pino Custódio/Estação Teatral,

enc. Nuno Pino Custódio, Estação Teatral, 2012

(37 > Joana Poejo, Tiago Poiares e Roberto Querido),

fot. Óscar Martins.

38 > (Filipe Eusébio e Tiago Poiares),

fot. Francisca Aranda.

39 > (Sara Gabriel, Joana Poejo, Roberto Querido,

Tiago Poiares e Filipe Eusébio),

fot. Óscar Martins.

$40>$ (Roberto Querido e Tiago Poiares),

fot. Nuno Pino Custódio. 

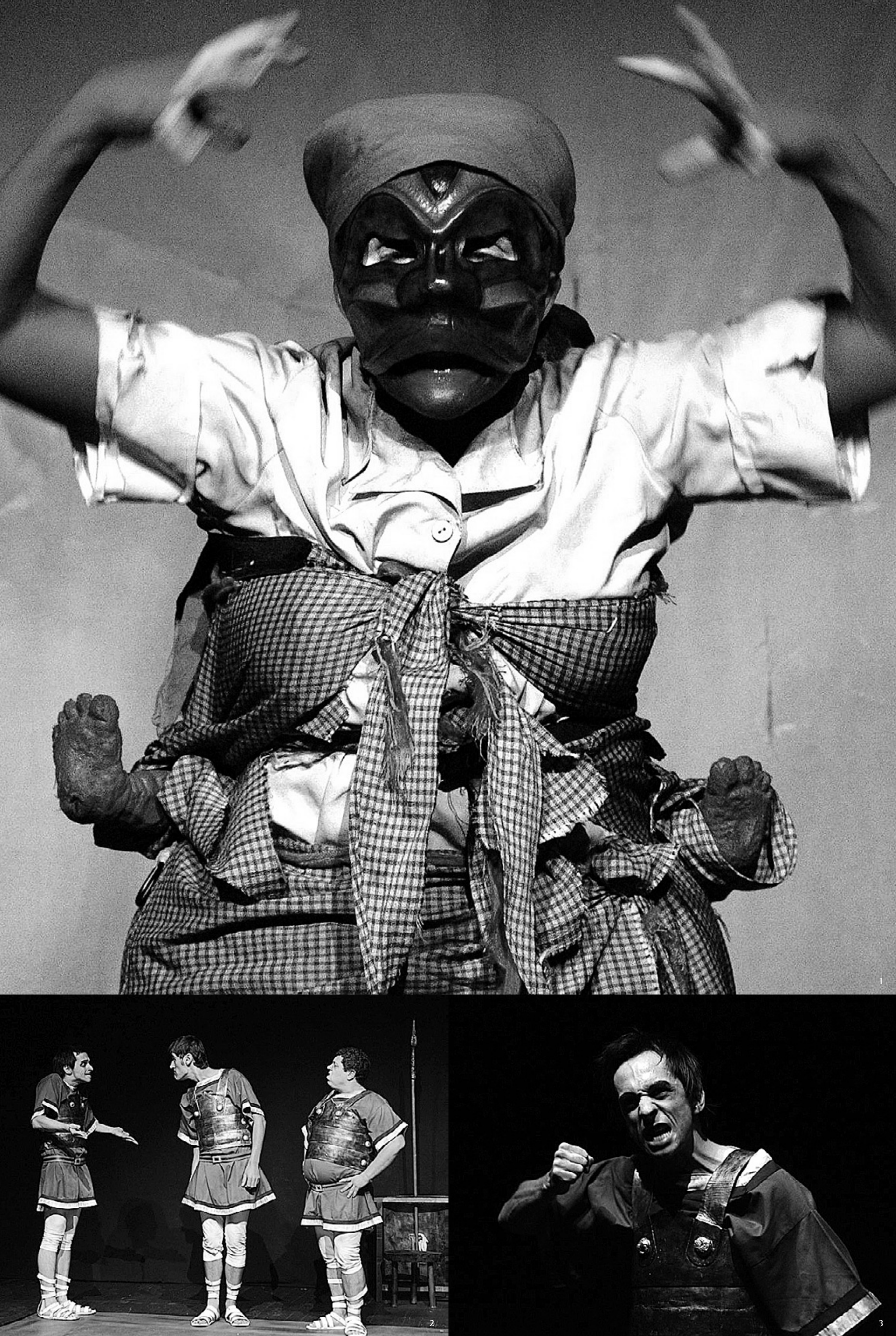

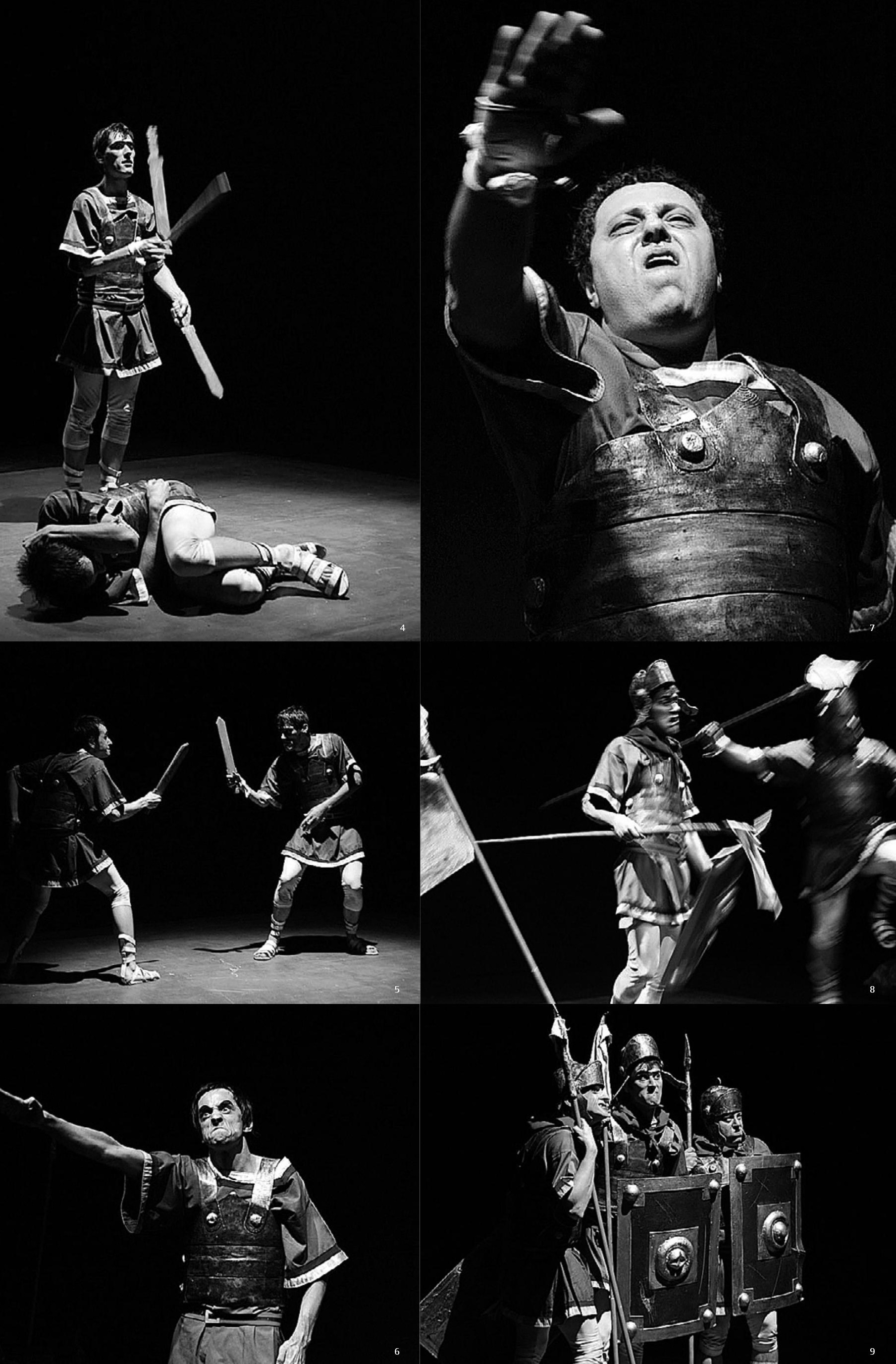

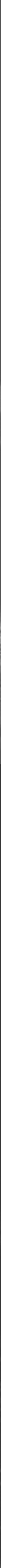

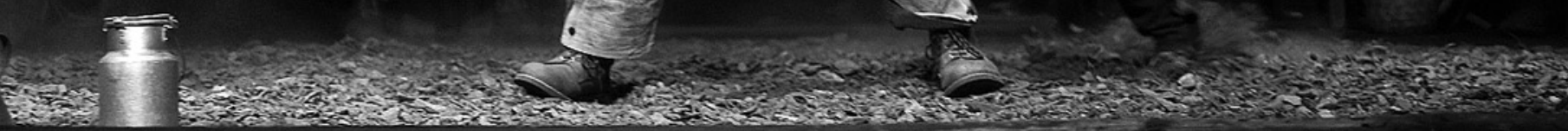



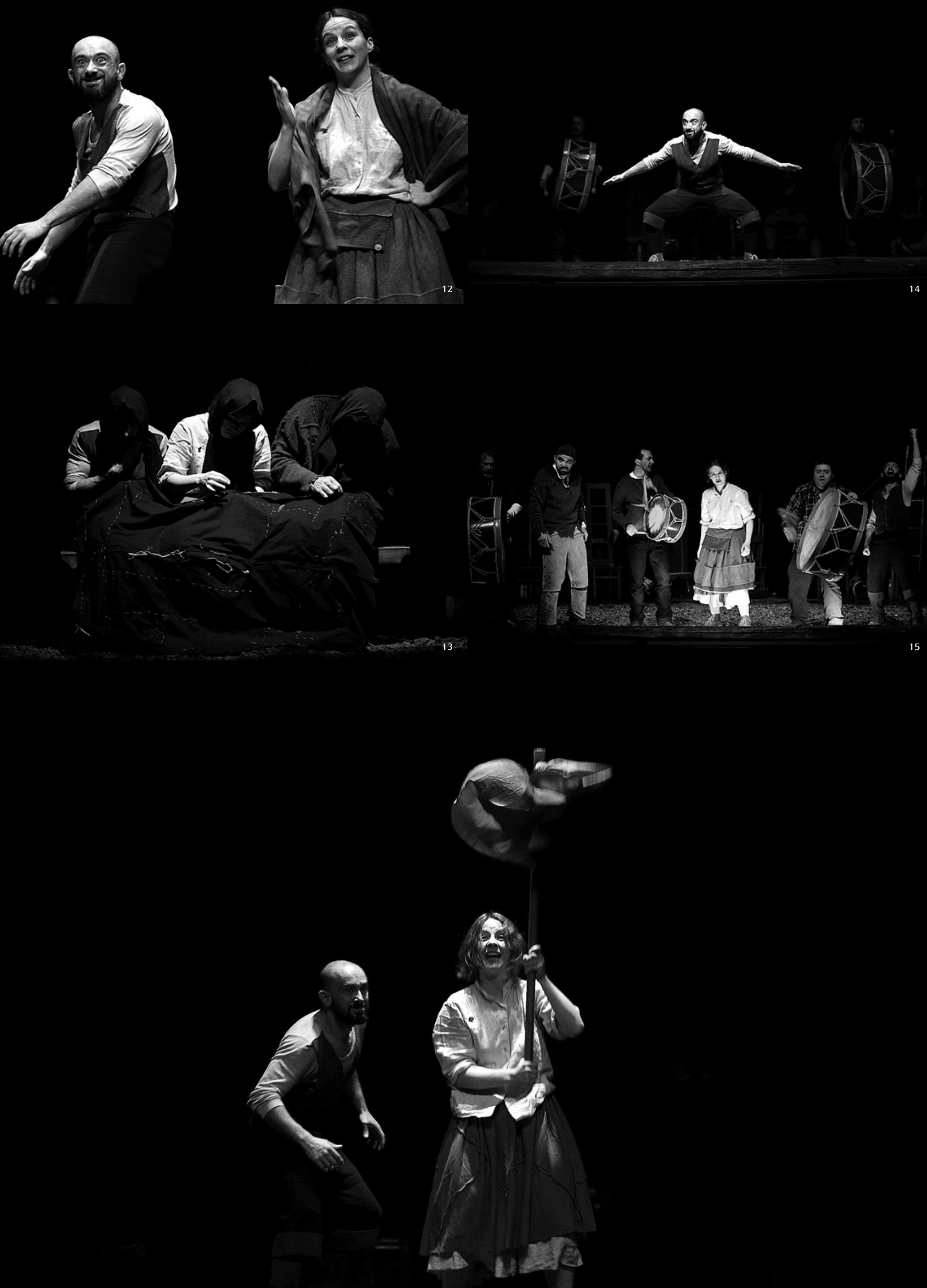

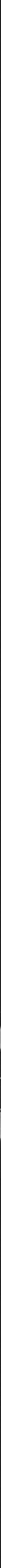

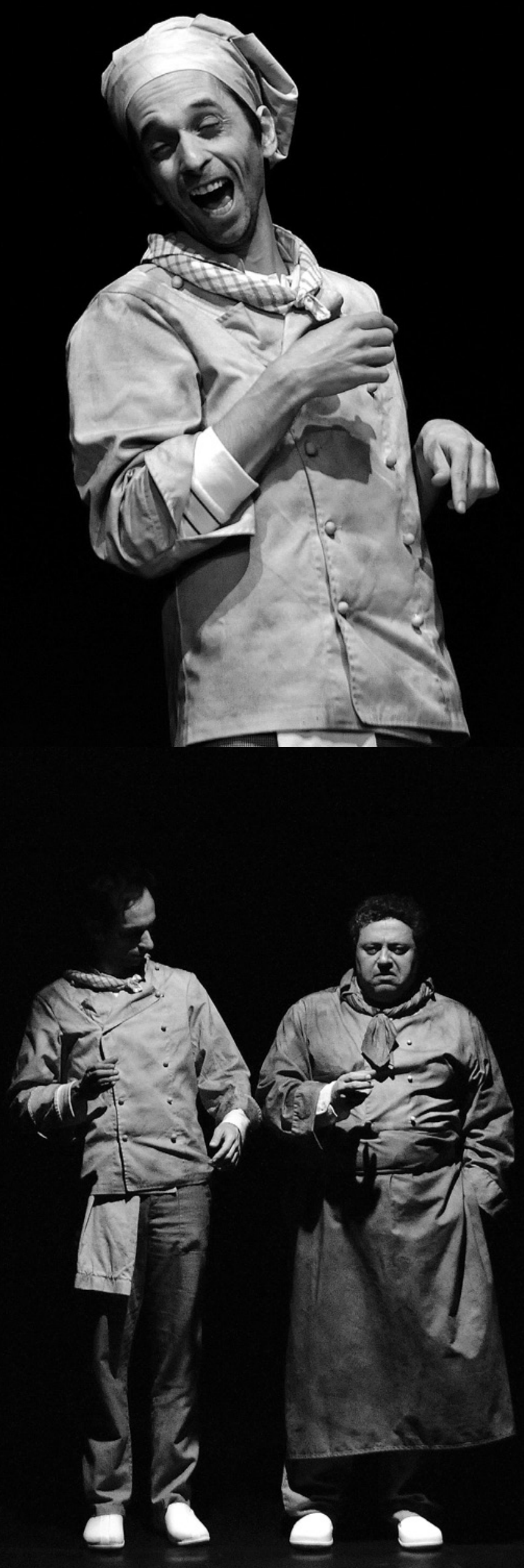


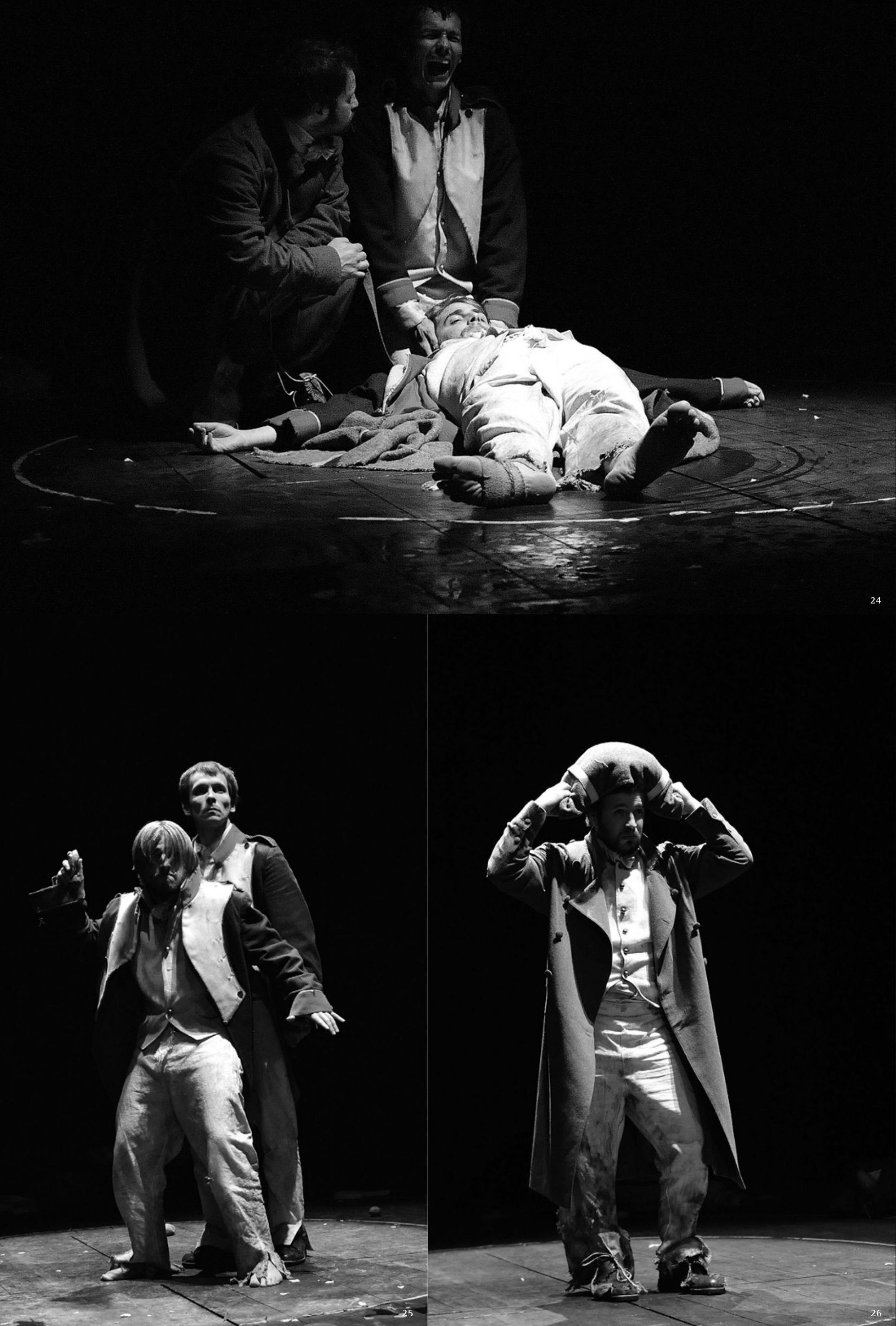



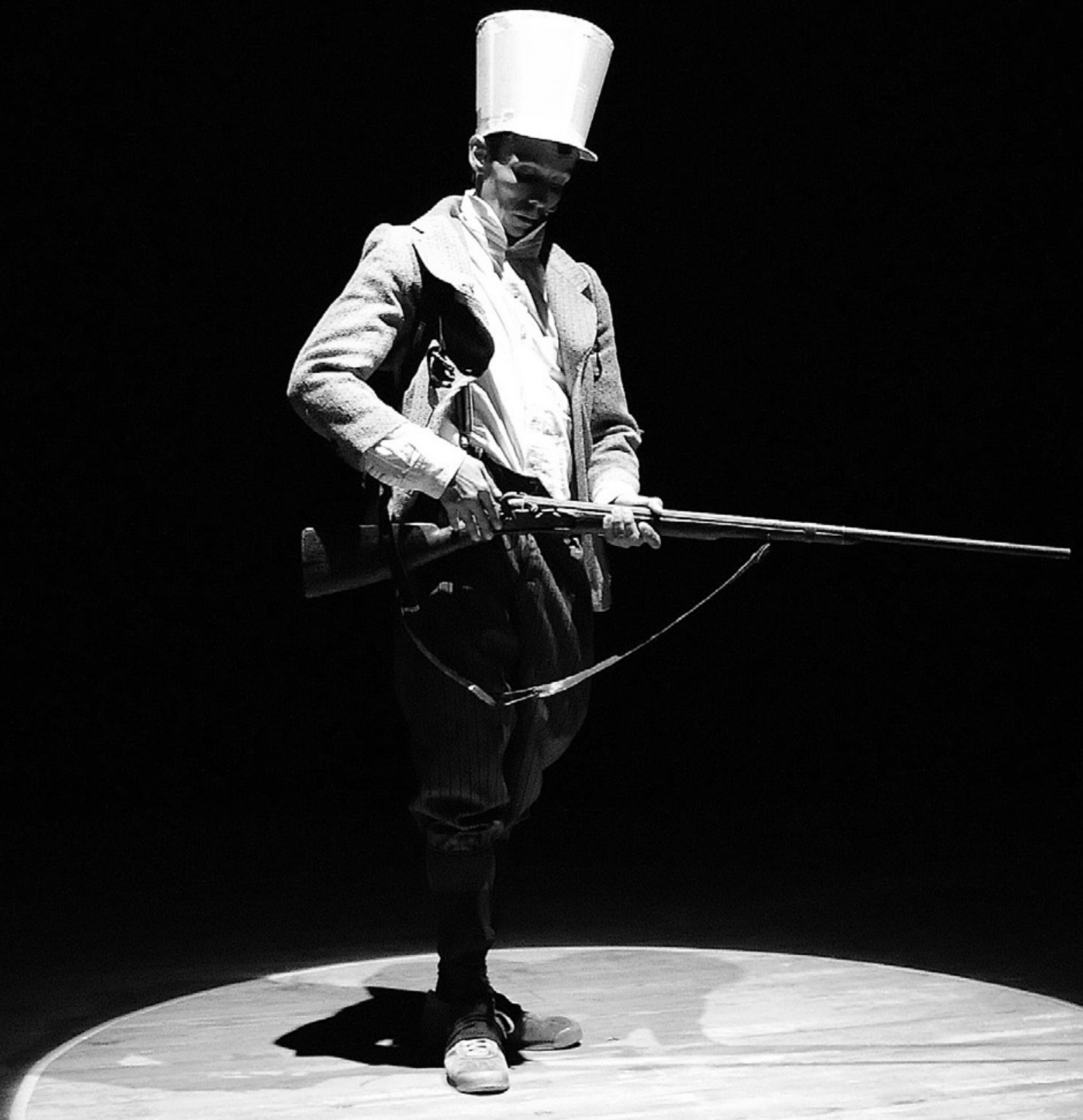

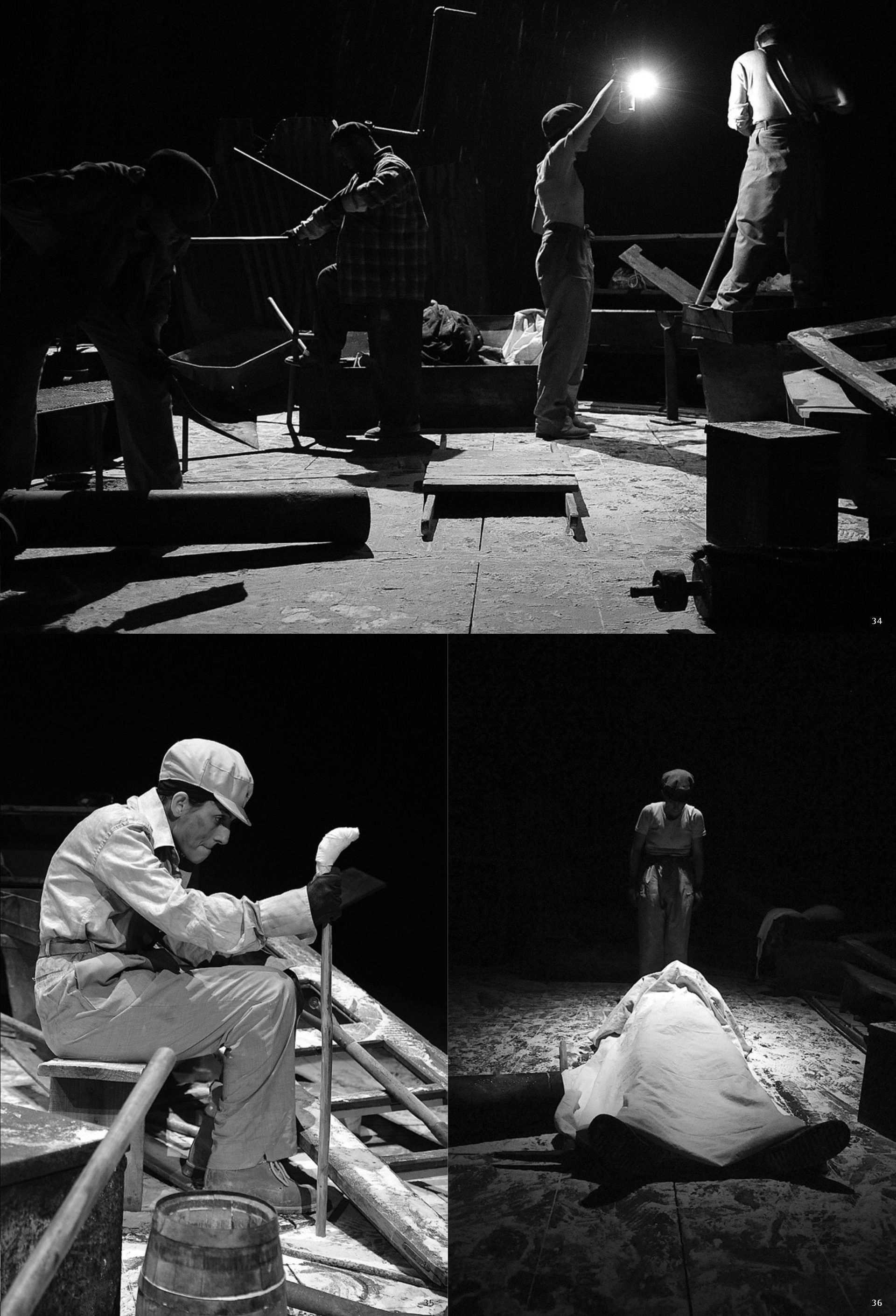

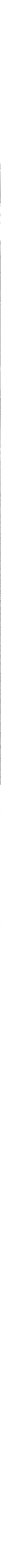